\title{
Paradigmas e interesses do conhecimento na Ciência da Informação: um estudo sobre as dissertações de mestrado do Programa de Pós-Graduação em Ciência da Informação da Universidade Federal de Pernambuco (2011 a 2013)
}

Hyllane Maria Salgueiro

Tecnóloga em Turismo pelo Instituto Federal de Alagoas. Graduada em Comunicação Social pela Universidade Federal de Alagoas. Mestre em Ciência da Informação pela Universidade Federal de Pernambuco

André Felipe de Albuquerque Fell

\begin{abstract}
Bacharel em Administração de Empresas pela Faculdade de Ciências da Administração de Pernambuco (FCAP / UPE).Especialização em Engenharia da Qualidade pela Universidade Federal de Pernambuco (UFPE).Mestrado em Administração pela Universidade Federal de Pernambuco (UFPE).Doutorado em Administração também pela Universidade Federal de Pernambuco (UFPE)Professor Adjunto da Universidade Federal de Pernambuco
\end{abstract}

http://dx.doi.org/10.1590/1981-5344/2416

Na trajetória histórica da ciência, inúmeras foram as perspectivas utilizadas no esforço de compreensão dos fenômenos da natureza intrínsecos ao processo de construção do conhecimento científico. Admitindo a multiplicidade de seus objetos investigados, 0 conhecimento científico veio sendo ramificado em ciências particulares do saber, estando elas relacionadas em duas categorias: ciências formais e ciências empíricas, incluída nesta última categoria, as chamadas Ciências Sociais Aplicadas, área na qual a Ciência da Informação (CI) encontra-se inserida. Sendo assim, a presente pesquisa buscou, a partir do estudo da produção acadêmica do campo da Ciência da Informação, compreender a 
Paradigmas e interesses do conhecimento na Ciência da Informação: um estudo sobre as dissertações de mestrado do Programa de PósGraduação em Ciência da Informação da Universidade Federal de Pernambuco (2011 a 2013)
Hyllane Maria Salgueiro; André Felipe de Albuquerque Fell

natureza paradigmática das pesquisas no contexto da Ciência da Informação, bem como o interesse de produção do conhecimento nas pesquisas analisadas. Como corpus de estudo, optou-se por analisar as dissertações defendidas no Programa de Pós-Graduação em Ciência da Informação (PPGCI) da Universidade Federal de Pernambuco (UFPE), compreendendo o período entre os anos de 2011 a 2013. Elencadas as 26 dissertações defendidas entre o período mencionado, constatou-se a predominância do paradigma positivista orientado, majoritariamente, por um viés de interesse técnico.

Palavras-chave: Pós-graduação em Ciência da Informação; Ciência da Informação; Dissertações de mestrado PPGCI/UFPE.

\section{Paradigms and interests of knowledge in Information Science: a study on master's theses in the Graduate Program in Information Science from the Federal University of Pernambuco (2011-2013)}

In the historical trajectory of science, numerous were the perspectives used in the effort to understand the phenomena of nature intrinsic to the scientific knowledge construction process. Admitting the multiplicity of its investigation objects, scientific knowledge has come to be branched in particular sciences knowledge, as they were listed in two categories: formal sciences and empirical sciences, including in the latter category, calls Social Sciences, an area in which science Information (CI) is inserted. Thus, the present study sought from the study of the academic research field of information science, understand the paradigmatic nature of research in the context of Information Science, as well as the interest of knowledge production in the analyzed studies. As study corpus, we chose to analyze the dissertations in the Program of Graduate Studies in Information Science (PPGCI) of the Federal University of Pernambuco (UFPE), 
Paradigmas e interesses do conhecimento na Ciência da Informação: um estudo sobre as dissertações de mestrado do Programa de PósGraduação em Ciência da Informação da Universidade Federal de Pernambuco (2011 a 2013)

covering the period between the years 2011 to 2013 listed the 26 dissertations defended between the mentioned period, there was a predominance of positivist paradigm oriented, mainly, by a bias of technical interest.

Keywords: Graduate in Information Science; Information Science; Master's thesis PPGCI/UFPE.

Recebido em 03.05.2015 Aceito em 23.07.2015

\section{Introdução}

Na trajetória histórica da ciência, inúmeras foram as perspectivas utilizadas no esforço de compreensão dos fenômenos da natureza intrínsecos ao processo de construção do conhecimento científico. Processo este que veio se constituindo de maneira distinta em cada contexto histórico, buscando atender, de maneira geral, aos interesses da sociedade e objetivos da comunidade científica. Diante disso, os diversos métodos e modos de realizar a atividade científica possibilitaram o debate e reflexão entre filósofos e sociólogos contemporâneos que, por conseguinte, exprimiram seus posicionamentos sobre os distintos modos de se fazer ciência (CORAZZA; NEVES; RAMOS, 2009).

Durante a Idade Média, o esforço de construção do conhecimento científico encontrava-se sobre forte influência da Igreja Católica. Enquanto a autoridade e o poder exercidos pela Igreja impunham suas doutrinas e dogmas como verdades absolutas, poucos foram os estudos e publicações acumuladas por um saber dito científico, uma vez que grande parte das informações encontrava-se retida ainda pelos eruditos eclesiásticos. Somente no século XVIII, após o III Concílio de Latrão, a Igreja Católica reconheceu os limites das escolas clericais e permitiu, ainda sob o seu controle, a licença docente a todos que fossem considerados aptos por ela, originando assim as primeiras universidades, o que possibilitou um maior incentivo para o posterior desenvolvimento do conhecimento científico e fortalecimento dos centros universitários (PRIMON et al., 2002).

Com o advento do Iluminismo, o chamado século das luzes promoveu uma nova reflexão filosófica e cultural com o confronto do pensamento lógico-racional aos preceitos dogmáticos ditados pela Igreja até àquele momento. Embora possa ter existido certo avanço nas chamadas Ciências Naturais, nesse período, ainda eram limitados os estudos, informações e conceitos estipulados pela comunidade científica, uma vez que essa ainda sofria significativas pressões religiosas e ainda direcionava boa parte do conhecimento às investigações contrárias à 
Paradigmas e interesses do conhecimento na Ciência da Informação: um estudo sobre as dissertações de mestrado do Programa de PósGraduação em Ciência da Informação da Universidade Federal de Pernambuco (2011 a 2013)
Hyllane Maria Salgueiro; André Felipe de Albuquerque Fell

objetividade e rigor característico dos métodos utilizados pelas Ciências Naturais (HEER, 1968).

O objetivismo característico às Ciências Naturais apresenta como princípio basilar a explicação da natureza por meio de rigorosas observações atribuídas no que Kuhn (2011) pontua como determinismo lógico. Por conseguinte, o objetivismo serviu como pano de fundo para o processo de construção intelectual do conhecimento a partir de uma busca positiva do mesmo. Em meados do século XVII, o surgimento e desenvolvimento da chamada Ciência Moderna favoreceu os pressupostos positivistas circunscritos na linearidade do método quantitativo onde somente seria considerado um fato científico o objeto de estudo ou investigação passível de ser quantificado ou mensurado. Gil (2008) concebe, de maneira geral, a ciência como um meio ou caminho para a busca do conhecimento. Entretanto, uma síntese objetiva sobre a definição da ciência em si torna-se, praticamente, uma discussão insolúvel.

Diante de seu desenvolvimento e admitindo a multiplicidade de seus objetos investigados, o conhecimento científico passou a ser ramificado em ciências particulares do saber que, na visão do autor supracitado, encontram-se divididas em duas categorias: ciências formais e ciências empíricas, estando nesta última, as Ciências Sociais Aplicadas, área na qual a Ciência da Informação (CI) encontra-se inserida (GIL, 2008).

É consenso afirmar que a evolução e construção do conceito epistemológico da CI estiveram desde seus primórdios associadas, sobretudo, ao estudo referente às Tecnologias da Informação e Comunicação (TIC), traço histórico que, possivelmente, contribuiu para a formação de um campo com características inter e multidisciplinar. Daí, seis correntes teóricas são identificadas no percurso histórico da CI, estas classificadas em: teoria matemática da informação e comunicação; teoria sistêmica; teoria crítica; teoria da representação; estudos relacionados à comunicação científica e, por último, os estudos de usuário (ARAÚJO, 2009). Assim, percebe-se inicialmente a justificada dificuldade em se estabelecer um conceito único, métodos próprios e limites bem delimitados, uma vez que outras áreas do conhecimento tais quais a informática e a biblioteconomia contribuíram conforme seus preceitos e fundamentos tornando assim, bastante heterogêneo o espaço teórico, metodológico e epistemológico da Ciência da Informação (PINHEIRO; LOUREIRO, 1995).

Para a realização da presente pesquisa, foi possível observar características importantes quanto à produção científica na área da CI, segundo estudo de sua produção acadêmica, sendo tomado como objeto de estudo as 26 dissertações de mestrado defendidas entre o período de 2011 a 2013 no Programa de Pós-Graduação em CI da Universidade Federal de Pernambuco a partir da classificação dos paradigmas 
Paradigmas e interesses do conhecimento na Ciência da Informação: um estudo sobre as dissertações de mestrado do Programa de PósGraduação em Ciência da Informação da Universidade Federal de Pernambuco (2011 a 2013)

elaborados por Guba e Lincoln (1994) junto à Teoria do Conhecimento de Habermas (1971).

Conforme a taxonomia traçada por Guba e Lincoln (1994), o posicionamento do pesquisador, tomando como ponto inicial os aspectos ontológicos, metodológicos e epistemológicos estão delineados conforme os paradigmas classificados em: positivista; pós-positivista; teoria crítica e; paradigma construtivista. Enquanto suporte teórico utilizado concomitantemente à taxonomia de Guba e Lincoln (1994), a Teoria do Conhecimento de Habermas parte do pressuposto de que o positivismo em si "desreferencializa o sujeito pensante em nome de uma ciência matematizada e exata" (MEDEIROS; MARQUES, 2003, p. 3). Sendo um dos maiores críticos do positivismo, Habermas (1971) sugere que todo o conhecimento é induzido e orientado por interesses cuja síntese explicativa de cada um norteou a composição do quadro de análise das dissertações defendidas (RODRIGUES FILHO, 1997).

\section{Análise do corpus de investigação: estudo de caso sobre as dissertações do Programa de Pós-Graduação da Universidade Federal de Pernambuco}

Para a análise desta pesquisa, o corpus investigado foi composto por 26 dissertações de mestrado apresentadas e defendidas no Programa de Pós-graduação em Ciência da Informação da Universidade Federal de Pernambuco entre os anos de 2011 a 2013 (Quadro 1). Por se tratar de um Programa de Pós-graduação recente, a investigação sustentou-se na análise das dissertações durante o período já mencionado por conta da possibilidade de reflexão e autorreflexão no contexto do PPGCI/UFPE sem deixar de considerar as múltiplas condições de perspectivas e distintos modos de realização das pesquisas. Assim, a partir da descrição e detalhamento dos achados relacionados à presente pesquisa, pretende-se expor os seus resultados cuja análise poderá servir de preceitos iniciais aos sujeitos participantes e pesquisadores no contexto do PPGCI/UFPE, além da possibilidade de formatação, elaboração e auxílio na abertura de um provável curso de doutorado. Ademais, a elaboração e efetuação da codificação apresentada logo abaixo objetivou formular uma melhor representação do conteúdo das dissertações investigadas com o propósito de, organizadamente e sistematicamente, analisa-las. Além disso, a mesma codificação situada após os nomes dos discentes refere-se, respectivamente, à linha de pesquisa, iniciais dos discentes, pesquisador e ano de defesa. 
Paradigmas e interesses do conhecimento na Ciência da Informação: um estudo sobre as dissertações de mestrado do Programa de PósGraduação em Ciência da Informação da Universidade Federal de Pernambuco (2011 a 2013)

\section{Quadro 1 - As dissertações do PPGCI/UFPE defendidas (2011 a 2013) nas duas linhas de pesquisa existentes}

\begin{tabular}{|c|c|c|c|c|c|c|}
\hline $\begin{array}{c}\text { Turm } \\
\mathbf{a}\end{array}$ & $\begin{array}{l}\text { Linha de } \\
\text { Pesquisa }\end{array}$ & $\begin{array}{l}\text { Data de } \\
\text { Defesa }\end{array}$ & Orientador (a) & Título da Dissertação & Discente & Codificação \\
\hline \multirow{9}{*}{2009} & Linha 1 & $21 / 09 / 11$ & $\begin{array}{l}\text { Prof. Lourival } \\
\text { Holanda }\end{array}$ & $\begin{array}{l}\text { Memória e } \\
\text { esquecimento na } \\
\text { Ciência da Informação: } \\
\text { um estudo exploratório }\end{array}$ & $\begin{array}{l}\text { Adriana } \\
\text { Buarque de } \\
\text { Holanda }\end{array}$ & [L1(ABH)2011] \\
\hline & Linha 2 & $22 / 09 / 11$ & $\begin{array}{l}\text { Prof. Fábio } \\
\text { Mascarenhas } \\
\text { e Silva }\end{array}$ & $\begin{array}{l}\text { Registros de marcas da } \\
\text { Junta Comercial do } \\
\text { Estado de Pernambuco: } \\
\text { um olhar semântico para } \\
\text { a organização de um } \\
\text { acervo histórico }\end{array}$ & $\begin{array}{l}\text { Ana Claúdia } \\
\text { Gouveia } \\
\text { Araújo }\end{array}$ & $\begin{array}{l}\text { [L2(ACGA)201 } \\
\text { 1] }\end{array}$ \\
\hline & Linha 1 & $16 / 09 / 11$ & $\begin{array}{l}\text { Prof. Denis } \\
\text { Antônio de } \\
\text { Mendonça } \\
\text { Bernardes }\end{array}$ & $\begin{array}{l}\text { SUDENE - informação e } \\
\text { educação em } \\
\text { Pernambuco } 1960 \text { - } \\
1980\end{array}$ & $\begin{array}{l}\text { Ângela } \\
\text { Cristina } \\
\text { Moreira do } \\
\text { Nascimento }\end{array}$ & $\begin{array}{l}\text { [L1(ACMN)201 } \\
\text { 1] }\end{array}$ \\
\hline & Linha 1 & $06 / 09 / 11$ & $\begin{array}{l}\text { Prof }{ }^{a} \text {. Joana } \\
\text { Coeli Ribeiro } \\
\text { Garcia }\end{array}$ & $\begin{array}{l}\text { Políticas de gestão de } \\
\text { periódicos científicos } \\
\text { eletrônicos da UFPE no } \\
\text { contexto da tecnologia } \\
\text { digital }\end{array}$ & $\begin{array}{l}\text { Giane da Paz } \\
\text { Ferreira Silva }\end{array}$ & $\begin{array}{l}\text { [L1(GPFS)201 } \\
1]\end{array}$ \\
\hline & Linha 1 & $16 / 09 / 11$ & $\begin{array}{l}\text { Profa. Maria } \\
\text { Cristina } \\
\text { Guimarães } \\
\text { Oliveira }\end{array}$ & $\begin{array}{l}\text { Políticas públicas - } \\
\text { preservação de } \\
\text { manifestações culturais: } \\
\text { o papel social da } \\
\text { FUNDARPE }\end{array}$ & $\begin{array}{l}\text { Helena } \\
\text { Azevedo }\end{array}$ & [L1(HA)2011] \\
\hline & Linha 2 & $02 / 09 / 11$ & $\begin{array}{l}\text { Prof. Renato } \\
\text { Fernandes } \\
\text { Corrêa }\end{array}$ & $\begin{array}{l}\text { Aplicações de } \\
\text { certificação digital no } \\
\text { Recife: perspectivas em } \\
\text { Ciência da Informação }\end{array}$ & $\begin{array}{l}\text { Sanderson } \\
\text { Lopes } \\
\text { Dorneles }\end{array}$ & [L2(SLD)2011] \\
\hline & Linha 1 & $29 / 09 / 11$ & $\begin{array}{c}\text { Prof. Carlos } \\
\text { Xavier de } \\
\text { Azevedo Netto }\end{array}$ & $\begin{array}{l}\text { O microfilme e o digital: } \\
\text { as duas faces da } \\
\text { preservação }\end{array}$ & $\begin{array}{l}\text { Sandra Maria } \\
\text { Veríssimo } \\
\text { Soares }\end{array}$ & $\begin{array}{l}\text { [L1(SMVS)201 } \\
1]\end{array}$ \\
\hline & Linha 1 & $16 / 09 / 11$ & $\begin{array}{l}\text { Profa }{ }^{a} \text {. Maria } \\
\text { Cristina } \\
\text { Guimarães } \\
\text { Oliveira }\end{array}$ & $\begin{array}{l}\text { Informação e memória: } \\
\text { registros documentais } \\
\text { da FUNDARPE } 2003 \text { - } \\
2009\end{array}$ & $\begin{array}{l}\text { Simone Rosa } \\
\text { de Oliveira }\end{array}$ & [L1(SRO)2011] \\
\hline & Linha 1 & $02 / 09 / 11$ & $\begin{array}{l}\text { Prof. Marcos } \\
\text { Galindo Lima }\end{array}$ & $\begin{array}{l}\text { Acesso livre: um olhar } \\
\text { sobre a preservação } \\
\text { digital no Brasil }\end{array}$ & $\begin{array}{l}\text { Susimery Vila } \\
\text { Nova Silva }\end{array}$ & $\begin{array}{l}\text { [L1(SVNS)201 } \\
1]\end{array}$ \\
\hline \multirow[t]{5}{*}{2010} & Linha 1 & $29 / 02 / 12$ & $\begin{array}{l}\text { Prof. Marcos } \\
\text { Galindo Lima }\end{array}$ & $\begin{array}{l}\text { Análise de risco: uma } \\
\text { metodologia a serviço } \\
\text { da preservação digital }\end{array}$ & $\begin{array}{l}\text { Fanny do } \\
\text { Couto Ribeiro }\end{array}$ & [L1(FCR)2012] \\
\hline & Linha 2 & $28 / 02 / 12$ & $\begin{array}{l}\text { Prof. André } \\
\text { Felipe de } \\
\text { Albuquerque } \\
\text { Fell }\end{array}$ & $\begin{array}{l}\text { Análise das melhorias } \\
\text { percebidas na gestão da } \\
\text { informação com o uso } \\
\text { da memória } \\
\text { organizacional existente } \\
\text { na implantação de } \\
\text { inteligência competitiva: } \\
\text { o caso do núcleo } \\
\text { integrado de negócios } \\
\text { do ITEP }\end{array}$ & $\begin{array}{l}\text { Gustavo } \\
\text { Henrique de } \\
\text { Aragão } \\
\text { Ferreira }\end{array}$ & $\begin{array}{l}\text { [L2(GHAF)201 } \\
\text { 2] }\end{array}$ \\
\hline & Linha 2 & $23 / 03 / 12$ & $\begin{array}{l}\text { Prof. Renato } \\
\text { Fernandes } \\
\text { Corrêa }\end{array}$ & $\begin{array}{l}\text { Bibliotecas digitais e } \\
\text { redes sociais } \\
\text { acadêmicas: motivos } \\
\text { para integração }\end{array}$ & $\begin{array}{l}\text { Jônatas Souza } \\
\text { de Abreu }\end{array}$ & [L2(JSA)2012] \\
\hline & Linha 1 & $08 / 02 / 12$ & $\begin{array}{c}\text { Prof }{ }^{a} \text {. Gilda } \\
\text { Maria } \\
\text { Whitaker Verri }\end{array}$ & $\begin{array}{l}\text { Produção estética de } \\
\text { conhecimento e uso } \\
\text { social da herança } \\
\text { cultural na biopaisagem } \\
\text { de Ladjane Bandeira }\end{array}$ & $\begin{array}{l}\text { Márcia } \\
\text { Cristina de } \\
\text { Miranda Lyra }\end{array}$ & $\begin{array}{l}\text { [L1(MCML)201 } \\
2]\end{array}$ \\
\hline & Linha 2 & $08 / 02 / 12$ & $\begin{array}{c}\text { Prof. Fábio } \\
\text { Mascare-nhas } \\
\text { e Silva }\end{array}$ & $\begin{array}{l}\text { A representação da } \\
\text { memória científica da } \\
\text { Ciência da Informação } \\
\text { brasileira: um estudo }\end{array}$ & $\begin{array}{l}\text { Marilucy da } \\
\text { Silva Ferreira }\end{array}$ & [L2(MSF)2012] \\
\hline
\end{tabular}


Paradigmas e interesses do conhecimento na Ciência da Informação: um estudo sobre as dissertações de mestrado do Programa de PósGraduação em Ciência da Informação da Universidade Federal de Pernambuco (2011 a 2013)
Hyllane Maria Salgueiro; André Felipe de Albuquerque Fell

\begin{tabular}{|c|c|c|c|c|c|c|}
\hline & & & & $\begin{array}{l}\text { com as palavras-chave } \\
\text { do ENANCIB }\end{array}$ & & \\
\hline & Linha 2 & $24 / 08 / 12$ & $\begin{array}{l}\text { Prof }^{a} \text {. } \\
\text { Marivalde } \\
\text { Moacir } \\
\text { Francelin }\end{array}$ & $\begin{array}{l}\text { Comunicação da } \\
\text { informação científica em } \\
\text { novos espaços de } \\
\text { memória }\end{array}$ & $\begin{array}{l}\text { Marylu } \\
\text { Ferreira de } \\
\text { Souza }\end{array}$ & [L2(MFS)2012] \\
\hline & Linha 1 & $10 / 02 / 12$ & $\begin{array}{l}\text { Prof. Lourival } \\
\text { Pereira Pinto }\end{array}$ & $\begin{array}{l}\text { Informação e memória } \\
\text { na literatura de cordel: } \\
\text { produção e fluxo }\end{array}$ & $\begin{array}{l}\text { Vânia Ferreira } \\
\text { da Silva }\end{array}$ & [L1(VFS)2012] \\
\hline \multirow{10}{*}{2011} & Linha 1 & $28 / 02 / 13$ & $\begin{array}{l}\text { Prof. Marcos } \\
\text { Galindo Lima }\end{array}$ & $\begin{array}{l}\text { Memórias em sais de } \\
\text { prata - fotografias do } \\
\text { Recife em instituições } \\
\text { memoriais }\end{array}$ & $\begin{array}{l}\text { Albertina } \\
\text { Otávia } \\
\text { Lacerda Malta }\end{array}$ & $\begin{array}{l}\text { [L1(AOLM)201 } \\
\text { 3] }\end{array}$ \\
\hline & Linha 2 & $28 / 02 / 13$ & $\begin{array}{l}\text { Prof. } \\
\text { Raimundo } \\
\text { Nonato } \\
\text { Macedo dos } \\
\text { Santos }\end{array}$ & $\begin{array}{l}\text { Produção de } \\
\text { conhecimento científico } \\
\text { em Engenharia Civil da } \\
\text { UFPE: estudo } \\
\text { bibliométrico de teses e } \\
\text { dissertações (2003- } \\
2012 \text { ) }\end{array}$ & $\begin{array}{l}\text { Cínthia Maria } \\
\text { Silva de } \\
\text { Holanda }\end{array}$ & $\begin{array}{l}\text { [L2(CMSH)201 } \\
\text { 3] }\end{array}$ \\
\hline & Linha 1 & $25 / 02 / 13$ & $\begin{array}{c}\text { Prof }{ }^{\text {a. Gilda }} \\
\text { Maria } \\
\text { Whitaker Verri }\end{array}$ & $\begin{array}{l}\text { Da partitura musical: um } \\
\text { olhar estético à } \\
\text { preservação da } \\
\text { memória }\end{array}$ & $\begin{array}{l}\text { Hugo Carlos } \\
\text { Cavalcanti }\end{array}$ & [L1(HCC)2013] \\
\hline & Linha 2 & $27 / 02 / 13$ & $\begin{array}{l}\text { Prof }{ }^{\text {a }} \text { Sandra } \\
\text { de } \\
\text { Albuquerque } \\
\text { Siebra }\end{array}$ & $\begin{array}{l}\text { Competência } \\
\text { informacional dos } \\
\text { docentes da UFPE }\end{array}$ & $\begin{array}{l}\text { Jaciane Freire } \\
\text { Santana }\end{array}$ & [L2(JFS)2013] \\
\hline & Linha 2 & $28 / 02 / 13$ & $\begin{array}{l}\text { Prof. André } \\
\text { Felipe de } \\
\text { Albuquerque } \\
\text { Fell }\end{array}$ & $\begin{array}{l}\text { Gestão da Informação } \\
\text { para a organização do } \\
\text { conhecimento no } \\
\text { terceiro setor: um } \\
\text { estudo de caso na } \\
\text { AERPA }\end{array}$ & $\begin{array}{l}\text { Malthus } \\
\text { Oliveira de } \\
\text { Queiroz }\end{array}$ & [L2(MOQ)2013] \\
\hline & Linha 1 & $18 / 02 / 13$ & $\begin{array}{l}\text { Prof. Fábio } \\
\text { Assis Pinho }\end{array}$ & $\begin{array}{l}\text { Dispositivos de memória } \\
\text { para informação jurídica: } \\
\text { análise de } \\
\text { procedimentos de } \\
\text { indexação }\end{array}$ & $\begin{array}{l}\text { Márcia Ivo } \\
\text { Braz }\end{array}$ & [L1(MIB)2013] \\
\hline & Linha 1 & $09 / 11 / 12$ & $\begin{array}{l}\text { Prof. Marcos } \\
\text { Galindo Lima }\end{array}$ & $\begin{array}{l}\text { A Gestão da Memoria: } \\
\text { as politicas públicas } \\
\text { culturais e a situação } \\
\text { dos museus no estado } \\
\text { de Pernambuco }\end{array}$ & $\begin{array}{l}\text { Mário Gouveia } \\
\text { Júnior }\end{array}$ & [L1(MGJ)2012] \\
\hline & Linha 2 & $18 / 02 / 13$ & $\begin{array}{l}\text { Prof. Fábio } \\
\text { Mascarenhas } \\
\text { e Silva }\end{array}$ & $\begin{array}{l}\text { A análise tipológica } \\
\text { como subsídio para } \\
\text { construção de } \\
\text { vocabulário controlado: } \\
\text { o caso do juízo de } \\
\text { órfãos do Recife (1824- } \\
1889 \text { ) }\end{array}$ & $\begin{array}{l}\text { Mônica Maria } \\
\text { de Pádua } \\
\text { Souto da } \\
\text { Cunha }\end{array}$ & $\begin{array}{l}\text { [L2(MMPSC)20 } \\
\text { 13] }\end{array}$ \\
\hline & Linha 1 & $27 / 02 / 13$ & $\begin{array}{l}\text { Profa . Maria } \\
\text { Cristina } \\
\text { Guimarães } \\
\text { Oliveira }\end{array}$ & $\begin{array}{l}\text { Comporta-mento e } \\
\text { competência } \\
\text { informacional infantil: o } \\
\text { olhar da Ciência da } \\
\text { Informação sobre a } \\
\text { geração digital }\end{array}$ & $\begin{array}{l}\text { Niliane Cunha } \\
\text { de Aguiar }\end{array}$ & [L1(NCA)2013] \\
\hline & Linha 1 & $27 / 02 / 13$ & $\begin{array}{l}\text { Prof. Marcos } \\
\text { Galindo Lima }\end{array}$ & $\begin{array}{l}\text { Hemeroteca esquecida: } \\
\text { fenômeno social do } \\
\text { esquecimento na } \\
\text { perspectiva da Ciência } \\
\text { da Informação }\end{array}$ & $\begin{array}{l}\text { Tony } \\
\text { Bernardino de } \\
\text { Macedo }\end{array}$ & [L1(TBM)2013] \\
\hline
\end{tabular}

Fonte: Elaborado pelos autores (2014).

Aqui, faz-se importante e coerente descrever que a escolha de investigação por parte desse conjunto de dissertações deveu-se ao fato de que, enquanto documento oficial, a dissertação em si representa a 
Paradigmas e interesses do conhecimento na Ciência da Informação: um estudo sobre as dissertações de mestrado do Programa de PósGraduação em Ciência da Informação da Universidade Federal de Pernambuco (2011 a 2013)

materialização final de um significativo processo de pesquisa acadêmico, em nível stricto sensu, no que tange o início da vida acadêmica de um pesquisador. Ademais, pode-se dizer que, em termos de análise e descrição mais detalhada quanto ao objeto de pesquisa, a dissertação apresenta-se como documento mais completo e complexo do que artigos ou ensaios científicos, por exemplo, porém não tão original quanto uma tese de doutorado (MUELLER; CAMPELLO; DIAS, 1996).

Conforme o site do PPGCI/UFPE, no período de tempo delimitado para o presente estudo, a linha 1 cujo teor contextual refere-se ao tema "pesquisa, memória da informação científica e tecnológica" apresentou a defesa de 16 dissertações envolvidas com a "produção de conhecimento sobre o uso social da herança cultural. Ênfase no uso de estoques de conhecimento produzidos em instituições de desenvolvimento regional e nacional e seu fluxo para fins sociopolíticos e econômicos" (PPGCI/ UFPE, s.d). Já a linha 2, cujo núcleo investigativo principal aprecia e contempla o estudo circunscrito sobre conteúdos relacionados à "comunicação e visualização da memória" possuía 10 dissertações defendidas no mesmo período de tempo delimitado, buscando compreender "os processos de comunicação da memória coletiva em distintos segmentos socioculturais".

Para a posterior análise das dissertações, a coleta dos documentos ocorreu de modo sistemático e organizado, respeitando o conteúdo exposto, os autores e propostas sugeridas por cada uma delas. Dessa maneira, ainda sobre a coleta de dados, observou-se que a mesma foi realizada, inicialmente, com o levantamento das dissertações do PPGCI/UFPE (2011 a 2013) seguindo a categorização definida a partir do ano, linha de pesquisa, data de defesa, orientador, título da dissertação, nome do discente e uma codificação voltada à representação de cada documento. É salutar expor que o necessário uso da codificação compreendeu um esforço investigativo por parte da pesquisadora com o objetivo de facilitar o enquadramento de cada uma das dissertações de acordo com os pressupostos teóricos tratados durante o período de realização desta pesquisa.

Preocupou-se ainda em compreender, a partir de uma leitura flutuante, o que Bardin (2004, p. 135) considera como "núcleo de sentido" do objeto estudado. Em termos mais específicos, a coleta de dados buscou compreender semanticamente o conteúdo das dissertações do PPGCI/UFPE (2011 a 2013) observando enquanto modo interpretativo as áreas temáticas subjacentes ao núcleo contextual (conteúdo) de cada dissertação.

\section{Paradigmas de pesquisa alternativos}

De maneira geral, a definição de paradigma é atribuída a Thomas Kuhn sendo compreendido como um sistema de crenças e valores 
Paradigmas e interesses do conhecimento na Ciência da Informação: um estudo sobre as dissertações de mestrado do Programa de PósGraduação em Ciência da Informação da Universidade Federal de Pernambuco (2011 a 2013)
Hyllane Maria Salgueiro; André Felipe de Albuquerque Fell

concebidos por um determinado grupo no qual sua formulação depende de preceitos estabelecidos simplesmente a partir da fé e visão de mundo (worldview) do pesquisador (FELL; XIMENES; FILHO, 2004). Para a presente pesquisa, uma das matrizes teóricas utilizadas foi a taxonomia formulada por Guba e Lincoln (1994) dirigida à pesquisa qualitativa, onde o posicionamento epistemológico, ontológico e metodológico do pesquisador concentra-se em um dos seguintes paradigmas: paradigma positivista; paradigma pós-positivista; paradigma relacionado à teoria crítica e; paradigma com caráter circunscrito na visão construtivista.

\section{Quadro 2 - Taxonomia dos Paradigmas na pesquisa qualitativa segundo Guba e Lincoln (1994)}

\begin{tabular}{|c|c|c|c|c|}
\hline Item & Positivismo & Pós-positivismo & Teoria Crítica & Construtivismo \\
\hline Ontologia & $\begin{array}{l}\text { Realismo } \\
\text { ingênuo. A } \\
\text { realidade é } \\
\text { "real" e } \\
\text { representável. }\end{array}$ & $\begin{array}{l}\text { Realismo crítico - } \\
\text { a realidade é } \\
\text { "real", mas } \\
\text { imperfeitamente e } \\
\text { probabilisticamen- } \\
\text { te representada. }\end{array}$ & \multirow{2}{*}{$\begin{array}{l}\text { Realismo } \\
\text { histórico - } \\
\text { realidade } \\
\text { virtual } \\
\text { moldada por } \\
\text { valores } \\
\text { seciais,- - - - - } \\
\text { políticos, } \\
\text { culturais, } \\
\text { étnicos, } \\
\text { econômicos, e } \\
\text { de gênero; } \\
\text { cristalizados } \\
\text { no tempo. } \\
\text { Transacional, } \\
\text { subjetivista; } \\
\text { os achados } \\
\text { são mediados } \\
\text { pelos valores }\end{array}$} & $\begin{array}{l}\text { Relativismo - } \\
\text { realidades locais } \\
\text { especificamente } \\
\text { construídas. }\end{array}$ \\
\hline Epistemologia & $\begin{array}{l}\text { Dualista, } \\
\text { objetivista: os } \\
\text { achados são } \\
\text { verdadeiros. }\end{array}$ & $\begin{array}{l}\text { Dualista } \\
\text { modificada; } \\
\text { objetivista; } \\
\text { tradição crítica, } \\
\text { comunidade; os } \\
\text { achados são } \\
\text { provavelmente } \\
\text { verdadeiros. }\end{array}$ & & $\begin{array}{l}\text { Transacional, } \\
\text { subjetivista; os } \\
\text { achados são criados }\end{array}$ \\
\hline Metodologia & $\begin{array}{l}\text { Experimental; } \\
\text { manipulativa; } \\
\text { verificação de } \\
\text { hipóteses; } \\
\text { preponderân- } \\
\text { cia de } \\
\text { métodos } \\
\text { quantitativos. }\end{array}$ & $\begin{array}{l}\text { Experimental } \\
\text { modificada, } \\
\text { manipulativa; } \\
\text { multiplismo crítico; } \\
\text { falsificação de } \\
\text { hipóteses, pode } \\
\text { incluir métodos } \\
\text { qualitativos. }\end{array}$ & $\begin{array}{l}\text { Dialógica, } \\
\text { dialética }\end{array}$ & $\begin{array}{l}\text { Hermenêutica, } \\
\text { dialética }\end{array}$ \\
\hline
\end{tabular}

Fonte: Adaptado de GUBA; LINCOLN (1994, p. 109).

No que tange a descrição dos paradigmas, tem-se que quanto ao aspecto ontológico, o positivismo é demarcado por uma realidade passível de apreensão ou compreensão, sendo chamado também de um realismo ingênuo. Epistemologicamente, no positivismo, a busca pelo conhecimento é tida como dualista objetivista, pois nesses termos, o sujeito epistêmico ou sujeito conhecedor apenas enxerga duas realidades contrárias que estão em constante conflito. A metodologia incorporada ao positivismo perpassa a experimentação, a manipulação e testes de hipóteses, sendo o método quantitativo o principal caminho tomado pelo pesquisador. $\mathrm{Na}$ 
Paradigmas e interesses do conhecimento na Ciência da Informação: um estudo sobre as dissertações de mestrado do Programa de PósGraduação em Ciência da Informação da Universidade Federal de Pernambuco (2011 a 2013)

trajetória percorrida pelo pesquisador envolvido nesse paradigma, a racionalidade exclui qualquer ameaça subjetiva que possa vir a contrariar a manipulação ou controle das hipóteses de pesquisa.

No pós-positivismo, ontologicamente, a realidade é quase semelhante ao positivismo. A diferença reside em que a realidade é percebida criticamente, sendo imperfeita probabilisticamente. O caráter epistemológico continua em parte dualista sendo modificado pela tradição crítica da comunidade. Por último, a metodologia no paradigma póspositivista supõe a falseabilidade de hipóteses e já pontua o aparecimento do método qualitativo. No quadrante ontológico, a teoria crítica e outros identifica uma realidade histórica - virtual construída por atores sociais, esta moldada por valores éticos, políticos, econômicos, sociais e culturais. No eixo epistemológico, o conhecimento encontrado é subjetivista, uma vez que as descobertas realizadas pelo pesquisador são mediadas pelos seus valores e costumes. Ademais, nesse paradigma, no eixo ligado à metodologia, aparece de maneira dialógica e dialética. Nesse paradigma assim como no construtivismo, não existe a separação entre os planos ontológicos e epistemológicos, uma vez que ambos se fundem por estarem ligados na prática e conceitualmente.

No paradigma construtivista, o plano ontológico assume uma realidade relativa sem deixar de considerar os desdobramentos sociais, especificando o contexto no qual ela está sendo observada e construída. Nesse sentido, conecta-se à busca do conhecimento a partir de um processo mais sofisticado, considerando os aspectos subjetivos do investigador e levando às possibilidades da criação dos achados. No eixo metodológico, respalda-se os métodos hermenêutico e dialético.

\section{Teoria do conhecimento de Habermas (1971)}

Habermas (1971) parte do pressuposto de que todo o conhecimento humano é induzido e dirigido por interesses. Medeiros e Marques (2003, p. 12) corroboram com as premissas habermasianas ressaltando que "a ausência da autorreflexão na construção do conhecimento é uma realidade latente nos contornos metodológicos do positivismo, impedindo que as ciências desenvolvam o seu caráter emancipador". Em outros termos, a busca por um conhecimento considerado exato, possivelmente racional, desenha-se normalmente sob a ótica rígida, esta enquadrada no contexto de uma lógica formal e matemática, onde o sujeito cognoscente do processo de busca do conhecimento é afastado ou excluído (HABERMAS, 1971). 
Paradigmas e interesses do conhecimento na Ciência da Informação: um estudo sobre as dissertações de mestrado do Programa de PósGraduação em Ciência da Informação da Universidade Federal de Pernambuco (2011 a 2013)

Quadro 3 - Os três domínios do conhecimento

\begin{tabular}{c|c|c|c}
\hline $\begin{array}{c}\text { Categorias do } \\
\text { Interesse Humano }\end{array}$ & $\begin{array}{c}\text { Espécie de } \\
\text { Conhecimento }\end{array}$ & Métodos de Pesquisa & Dimensão Social \\
\hline Técnico (predição) & $\begin{array}{c}\text { Instrumental (explicação } \\
\text { causal) }\end{array}$ & $\begin{array}{c}\text { Ciências Naturais (método } \\
\text { empírico - analítico) }\end{array}$ & Trabalho \\
\hline $\begin{array}{c}\text { Prático } \\
\text { (interpretação ou } \\
\text { entendimento) }\end{array}$ & Prático (entendimento) & $\begin{array}{c}\text { Pesquisa Interpretativa (método } \\
\text { hermenêutico) }\end{array}$ & Interação \\
\hline $\begin{array}{c}\text { Emancipatório } \\
\text { (crítica e liberação) }\end{array}$ & Emancipação (reflexão) & $\begin{array}{c}\text { Ciências Sociais Críticas (método } \\
\text { da Teoria Crítica) }\end{array}$ & Poder/autoridade \\
\hline
\end{tabular}

Fonte: Adaptado de RODRIGUES FILHO (1997).

Quanto ao quadro exposto anteriormente (Quadro 3), tem-se dispostos os três tipos de interesse do conhecimento humano, as características detalhadas enquanto ao tipo de ciência vinculada, o propósito destas e a dimensão social atrelada a cada uma delas. Cada categoria compreendeu um esforço investigativo por parte do pesquisador Rodrigues Filho (1997) quanto à distinção, orientação singular e/ou divergente relacionada a cada uma das categorias enquanto síntese referente à Teoria do Conhecimento de Habermas (1971).

A categoria orientada segundo um interesse técnico considera 0 conhecimento uma apreensão instrumental, objetiva e reducionista, normalmente associado ao caráter mensurável atrelado aos moldes e leis formuladas conforme as ciências da natureza e as ciências sociais, desde que ambas lidem com um conhecimento do tipo nomológico. Uma vez que esse tipo de interesse age com a premissa de um "saber técnico e utilizável" (HABERMAS, 1971, p. 212), tal interesse assume o desejo de domínio e controle da natureza numa espécie de busca e descoberta de leis rigorosamente estipuladas por meio da indução, causas descobertas a partir de inferências hipotéticas e, no que concerne o controle sobre a natureza, a previsão de efeitos (HABERMAS, 1971).

Já o interesse prático ou comunicativo parte do método hermenêutico e entende que a partir da interpretação e do entendimento mútuo entre os sujeitos cognoscentes é que se manifesta a interação, o diálogo e até mesmo o conflito entre indivíduos e grupos. Dentro desse interesse situam-se as chamadas Ciências Humanas. Ademais, o método ou técnica hermenêutica cuja práxis respalda-se no sentido de interação é mediada por um complexo conjunto simbólico contextualizado conforme o fenômeno da linguagem (HABERMAS, 1971).

Por fim, o interesse emancipatório respalda-se na proposta de uma reflexão a partir da crítica da sociedade por ela mesma. Este interesse manifesta-se e está direcionado, inicialmente, à autorreflexão individual e coletiva por assumir a proposta de um caráter libertador do indivíduo. Ademais, liga-se às ciências sociais ou ciências críticas encontrando pontos afins com a filosofia e psicologia devido ao seu caráter contestador. Dessa maneira, resulta em um interesse justificador e 
Paradigmas e interesses do conhecimento na Ciência da Informação: um estudo sobre as dissertações de mestrado do Programa de PósGraduação em Ciência da Informação da Universidade Federal de Pernambuco (2011 a 2013)

explicativo no sentido de busca por se fazer compreender a realidade por ela mesma. Aqui, o próprio sujeito cognoscente realiza a autorreflexão sem deixar de considerar as múltiplas formas de perceber o mundo levando-se a questionar, segundo premissas das ciências sociais, a realidade e o sentido do mundo da vida (HABERMAS, 1971).

\section{Procedimentos metodológicos}

A investigação predominante foi de caráter qualitativo com natureza interpretativa, tendo como estratégia principal o estudo de caso, além de se caracterizar como um estudo exploratório. Conforme o objeto de pesquisa escolhido, o estudo exploratório possui como primeira necessidade a explanação de um tema desconhecido ao pesquisador, de forma que tal exploração provoque no mesmo a elaboração de questões de pesquisas, além de instrumentos que the possibilitem realizar um futuro estudo descritivo (MATTARA, 2005, p. 84).

A pesquisa com foco ou abordagem qualitativa representa a escolha de um caminho a ser percorrido pelo pesquisador tendo em vista a compreensão do objeto de estudo conforme uma análise da realidade por meio de métodos e técnicas que buscam uma compreensão detalhada do objeto sem perder de vista o seu contexto histórico e social, o que corrobora com o estudo de caráter exploratório no que tange a perspectiva de descrever, classificar e interpretar o objeto conforme bases teóricas inicialmente assumidas pelo pesquisador (RUDIO, 1985, p. 57).

Enquanto procedimento adotado para investigação da seguinte pesquisa, optou-se pelo estudo de caso por ser identificado como uma estratégia de pesquisa coerente cujo enfoque principal configura-se em investigar "um fenômeno contemporâneo em profundidade e em seu contexto de vida real, especialmente quando os limites entre o fenômeno e o contexto não são claramente evidentes" (YIN, 2005, p. 39). Sendo assim, optou-se pela pesquisa interpretativa por conta dos seguintes aspectos: i) a pesquisa interpretativa corrobora diretamente com a premissa assumida por uma pesquisa de caráter qualitativo, principal atitude investigativa escolhida desde o início da presente pesquisa; ii) a pesquisa interpretativa ou hermenêutica correlacionada à pesquisa de essência crítica considera, primeiramente, o sujeito investigador ou pesquisador como agente social, isto é, sujeito dotado de uma subjetividade e bagagem histórica-social complexa e única; iii) em outras palavras, a hermenêutica atua de maneira inter-relacionada à experiência de vida do próprio investigador no processo de construção dinâmico do conhecimento e dos achados quais ele se propõe investigar. Dentro dessa perspectiva, o aspecto crítico correlacionado ao método interpretativo dispõe da exposição de elementos ocultos que quando elucidados principiam o surgimento do objetivo em "dizer o que é em vista do que 
Paradigmas e interesses do conhecimento na Ciência da Informação: um estudo sobre as dissertações de mestrado do Programa de PósGraduação em Ciência da Informação da Universidade Federal de Pernambuco (2011 a 2013)

ainda não é, mas que pode ser" (ORLIKOWSKI; BAROUDI, 1991; NOBRE, 2011, p. 9).

Acredita-se que os aspectos metodológicos supracitados assumiram uma postura mais adequada para a investigação sobre o conteúdo das dissertações defendidas e apresentadas dentro do PPGCI/UFPE justificada a proximidade da investigadora ao seu objeto de pesquisa tendo em vista o esforço de compreensão da natureza ou essência do mesmo, isto é, aspectos que corroboraram aos preceitos de uma investigação com caráter qualitativo.

Sendo assim, pontua-se os procedimentos da pesquisa conforme os seguintes passos: i) escolha da abordagem principal para a análise da investigação tendo sido escolhida a abordagem qualitativa segundo apontamentos já supracitados; ii) sendo escolhida a abordagem qualitativa, traçou-se o estudo de caso como estratégia de pesquisa; iii) para a coleta e análise de dados, optou-se pela divisão das dissertações sob os auspícios delimitados nas duas linhas de pesquisa constitutivas do PPGCI/UFPE; iv) assim, e de acordo com o percurso adotado pela investigadora, ocorreu a análise de conteúdo configurado à técnica circunscrita à base hermenêutica. Em outras palavras, pode-se dizer que a realização da técnica da análise de conteúdo reside na elaboração de interpretações acerca daquilo que está sendo estudado; tendo em vista a atenção principal aos significados das mensagens (BARDIN, 2004).

\section{Discussão dos Resultados}

Enquanto base teórica escolhida para a análise das dissertações do PPGCI/UFPE (2011 a 2013), tanto a taxonomia dos paradigmas alternativos (GUBA; LINCOLN, 1994) quanto a teoria do conhecimento (HABERMAS, 1971) convergem e dialogam entre si no sentido principal de encontro à crítica ao positivismo enquanto à percepção de mundo do pesquisador e, dentre outros aspectos, ao direcionamento à crítica ao modo positivista de fazer ciência. Além disso, uma possível superação deste paradigma pressupõe, sobretudo, a existência, discussão e a busca por validade de um maior pluralismo de perspectivas em se enxergar o mundo diferenciando-se, mais uma vez, dos moldes rígidos característicos à perspectiva positivista o que, por conseguinte, amplia as condições de uso do método qualitativo, aspecto ainda pouco evidente dentro da trajetória metodológica da pesquisa em Ciência da Informação (ARAÚjO, 2009).

Quanto à análise das dissertações, no primeiro momento, considerando o total das 26 dissertações, notou-se uma significativa presença de dissertações posicionadas no quadrante positivista, isto é, 15 dissertações contidas na linha 1 e 8 dissertações contidas na linha 2 cujo aspectos e indícios positivistas foram evidenciados. Ainda assim, foi 
Paradigmas e interesses do conhecimento na Ciência da Informação: um estudo sobre as dissertações de mestrado do Programa de PósGraduação em Ciência da Informação da Universidade Federal de Pernambuco (2011 a 2013)

possível identificar duas dissertações com indícios construtivistas (paradigma "construtivismo") e uma única dissertação configurada aos moldes semelhantes ao paradigma do pós-positivismo.

Nas dissertações defendidas dentro da linha 1 cujo tema debate questões relacionadas à memória da informação científica e tecnológica, foram identificadas 15 dissertações $(57,6 \%)$ classificadas como sendo positivistas ([L1(ABH)2011]; [L1(ACMN)2011]; [L1(GPFS)2011]; [L1(HA)2011]; [L1(SMVS)2011]; [L1(SRO)2011]; [L1(SVNS)2011]; [L1(FCR)2012]; [L1(MCML)2012]; [L1(AOLM)2013]; [L1(HCC)2013]; [L1(MIB)2013]; [L1(MGJ)2012];[L1(NCA)2013] e [L1(TBM)2013]), o que muito provavelmente significa dizer que foram encontrados elementos de caráter positivistas, tais como: i) a predisposição ao controle por meio da comprovação e verificação de hipóteses; ii) uso de métodos quantitativos. À guisa de exemplificação, alguns trechos representativos das dissertações defendidas foram extraídos das mesmas com o objetivo de classificá-las compreendendo de antemão as categorias anteriormente explanadas:

a partir das observações nas bibliotecas, é possível citar os elementos que podem ser refletidos em uma política de indexação para informação jurídica: adoção de um controle terminológico - uma vez que se opta pela especificidade, é necessário adotar um instrumento de controle do vocabulário, com o intuito de normalizar os descritores, especialmente quando se trata de uma área do conhecimento específica com tipos documentais também característicos, como é o caso do direito. Em todas as instituições observadas foi adotado um instrumento para controle do vocabulário, porém é feita uma ressalva no que tange a contextualização desses, uma vez que devem ser constituídos considerando a matéria que liga cada contexto e o modo como serão atualizados e avaliados esses instrumentos (BRAZ, 2013, p. 169).

A partir da visualização deste fragmento contido na dissertação [L1(MIB)2013], foram percebidas algumas evidências e vestígios de controle e verificação de hipóteses. Ainda sobre as dissertações contidas dentro da linha 1, é salutar observar que em 2 dissertações ([L1(HCC)2013] e [L1(MCML)2012]), a palavra "crítica" fez-se presente, no entanto, à medida que os desdobramentos foram se tecendo, percebese ainda que a finalidade maior continua a ser a investigação por meio do controle e verificação de hipóteses em detrimento de questões subjetivas à realidade dos respondentes.

Por outro lado, apenas uma dissertação defendida foi categorizada no paradigma construtivista. Neste caso específico e conforme percebido 
Paradigmas e interesses do conhecimento na Ciência da Informação: um estudo sobre as dissertações de mestrado do Programa de PósGraduação em Ciência da Informação da Universidade Federal de Pernambuco (2011 a 2013)
Hyllane Maria Salgueiro; André Felipe de Albuquerque Fell

abaixo, as análises desenvolvidas nesta dissertação ([L1(VFS)2012]) consideraram as especificidades da realidade local construída, possibilitando ainda a escuta de seus atores. Indícios que, mesmo sendo encontrados de maneira tímida, sugerem uma predisposição de superação do paradigma positivista no que concerne uma maior compreensão da realidade dos sujeitos nela envolvidos (GUBA; LINCOLN, 1994).

A CI ao estudar e analisar esses suportes informacionais da cultura popular oferece outros relatos da memória de um país como o Brasil, tão plural em sua cultura. Há dois conceitos importantes a serem analisados em suportes informacionais como o cordel, são eles: a informação da prática social, produzida pelo indivíduo que recebe ou busca informação, e através da utilização, produz e dissemina uma informação na qual insere uma interpretação e linguagem própria, como por exemplo, a poesia; a memória social. São relatos que não constam na memória coletiva oficial do país, mas que registram vozes diferentes que são importantes para a construção de uma memória coletiva comum a todos os grupos sociais. Por esta razão, é indispensável o resgate dos relatos sociais de grupos populares e culturais, no que diz respeito à construção e disseminação de seus relatos memoriais (SILVA, 2012, p. 114).

Quanto às dissertações defendidas na linha 2 (Comunicação e Visualização da Memória), identificou-se que 8 dissertações (equivalente a $30,7 \%$ do total de dissertações defendidas nas duas linhas) se enquadraram no modelo positivista ([L2(ACGA)2011]; [L2(SLD)2011]; [L2(GHAF)2012]; [L2(JSA)2012]; [L2(MSF)2012]; [L2(MSF)2012]; [L2(CMSH)2013]; [L2(MMPSC)2013]). As dissertações como [L2(CMSH)2013] e [L2(MMPSC)2013] apresentaram características e evidências positivistas quanto ao seu conteúdo, sendo possível também perceber uma disposição ao controle e à manipulação de hipóteses. Características que possivelmente estão associadas ao fato de que, sob os moldes positivistas, a informação é observada como "coisa", objeto concreto passível de manipulação e tratamento (ARAúJO, 2009).

Ainda na linha 2 foram identificadas duas dissertações segundo o modelo pós-positivista e o construtivista. Como exemplo, a dissertação [L2(JFS)2013] foi identificada e classificada no paradigma pós-positivista por seu autor (a) compreender que a realidade é real, mas imperfeita, isto é, não pode ser apreendida perfeita e totalmente. Nesse paradigma, considera-se que os achados serão provavelmente verdadeiros, 
Paradigmas e interesses do conhecimento na Ciência da Informação: um estudo sobre as dissertações de mestrado do Programa de PósGraduação em Ciência da Informação da Universidade Federal de Pernambuco (2011 a 2013)
Hyllane Maria Salgueiro; André Felipe de Albuquerque Fell

assumindo um posicionamento crítico da realidade sem a pretensão de elaborar leis ou generalizações.

Em termos metodológicos, a hermenêutica e a dialética estão presentes no paradigma construtivista, uma vez que esse pressupõe a compreensão mediada por parte do investigador e de seus respondentes. Tais características e elementos foram encontrados na dissertação [L2(MOQ)2013], cujo autor, ao observar questões pontuais e locais, relativizou os problemas encontrados tornando-se mediador no processo de investigação.

No que concerne as categorias de interesse humano sob à luz da Teoria do Conhecimento de Habermas (1971), houve uma significativa predominância do enfoque técnico nas dissertações (92\%), de maneira geral. Essas pistas permitiram reforçar a natureza das investigações realizadas tomadas ao objetivo do controle e a predição, em contraste aos interesses induzidos pelo pragmatismo (interesse prático) e o interesse emancipatório.

$\mathrm{Na}$ linha 1, dentro das dissertações analisadas foram classificadas 15 dissertações $(57,6 \%)$ orientadas segundo viés de interesse técnico ([L1(ABH)2011]; [L1(ACMN)2011]; [L1(GPFS)2011]; [L1(HA)2011]; [L1(SMVS)2011]; [L1(SRO)2011]; [L1(SVNS)2011]; [L1(FCR)2012]; [L1(MCML)2012]; [L1(AOLM)2013]; [L1(HCC)2013]; [L1(MIB)2013]; [L1(MGJ)2012]; [L1(NCA)2013]; [L1(TBM)2013]). Dessa maneira, podese dizer que houve a ênfase por controle e predição na maior parte das investigações atribuídas a essa linha de pesquisa. Aqui, o controle estava relacionado ao ato de prever ações, próprios aos métodos e premissas característicos às ciências da natureza.

Ainda na linha 1, apenas a dissertação [L1(VSF)2012] apresentou elementos relacionados ao interesse prático, isto é, nessa investigação pôde-se observar a interação entre o autor (pesquisador) e respondentes, possibilitando a ação, a escuta de opinião e perspectiva do sujeito enquanto autor do processo de pesquisa. Aqui, o entendimento dialético e hermenêutico consiste em compreender o sujeito como elemento mediador e ativo na interação ocorrida dentro da pesquisa.

Quanto à disposição das dissertações da linha 2 (comunicação e visualização da memória), 9 dissertações (34,6\%) nortearam seus interesses pelo aspecto técnico ([L2(ACGA)2011]; [L2(SLD)2011]; [L2(GHAF)2012]; [L2(JSA)2012]; [L2(MSF)2012]; [L2(MFS)2012]; [L2(CMSH)2013]; [L2(MMPSC)2013] e [L2(JFS)2013]). O predomínio do interesse técnico nessa linha atribui-se aos métodos utilizados normalmente pelas ciências da natureza. A investigação conforme predomínio de um interesse meramente técnico se abstém de levar em consideração a subjetividade, a complexidade, o contexto e as reflexões acerca do mundo no qual o sujeito cognoscente encontra-se circunscrito (FELL; XIMENES; FILHO, 2004). 
Paradigmas e interesses do conhecimento na Ciência da Informação: um estudo sobre as dissertações de mestrado do Programa de PósGraduação em Ciência da Informação da Universidade Federal de Pernambuco (2011 a 2013)
Hyllane Maria Salgueiro; André Felipe de Albuquerque Fell

Conforme demonstrado nesta pesquisa, a informação é uma importante aliada na atuação organizacional. Porém, apesar de - número de publicações na $\mathrm{CI}$ sobre o assunto ter aumentado, indicando o crescente interesse pelo tema, podese dizer que a gestão da informação ainda é um assunto em segundo plano na maioria das organizações. Esse quadro se acentua no tocando às organizações não governamentais, devido ao seu perfil e às suas características gerenciais: atuando no eixo de articulação entre o Estado, a comunidade e o setor produtivo, é natural que seu desempenho esteja atrelado a necessidades desses três setores, o que exige um maior cuidado na construção de suas práticas, no sentido de favorecer uma integração socialmente favorável a todos (QUEIROZ, 2013, p. 186).

O interesse prático, conduzido pela interação entre seus agentes (pesquisador - respondentes) parte da premissa proposta pela hermenêutica (HABERMAS, 1971). Conforme último trecho extraído da dissertação [L2(MOQ)2013] percebeu-se a partir da leitura desta dissertação aspectos conduzidos por interesses práticos, uma vez que os respondentes tiveram Voz produzindo, reproduzindo e denunciando possíveis elementos que, dificilmente, seriam encontrados caso a investigação estivesse dirigida por um interesse meramente técnico.

\section{Considerações finais}

Como objetivo geral da pesquisa, pretendeu-se realizar a análise da produção acadêmica em Ciência da Informação a partir das dissertações defendidas no Programa de Pós-Graduação em Ciência da Informação (PPGCI) da Universidade Federal de Pernambuco (UFPE), compreendendo o período de 2011 a 2013. Salienta-se que, ao analisar as dissertações do PPGCI/UFPE, pôde-se observar o predomínio de um paradigma essencialmente positivista. Isto é, de acordo com as análises realizadas, foram encontradas dissertações ontologicamente limitadas por um realismo ingênuo evidenciado conforme investigação de conteúdo dos documentos.

Nesse ponto, a realidade encarada sobre a condição positivista toma suas dimensões baseadas em noções binárias, isto é, acaba por acontecer a exclusão relacionada às múltiplas facetas atreladas ao mundo social e, consequentemente, às perspectivas dos atores envolvidos. Epistemologicamente, as dissertações se mostraram dualistas, ou seja, percebeu-se que 0 investigador e o objeto de pesquisa mantinham uma relação de independência, excluindo as possíveis falhas humanas e relativas intrínsecos ao processo de investigação. Em termos 
Paradigmas e interesses do conhecimento na Ciência da Informação: um estudo sobre as dissertações de mestrado do Programa de PósGraduação em Ciência da Informação da Universidade Federal de Pernambuco (2011 a 2013)

metodológicos, houve uma predominância pela verificação e controle de hipóteses, elucidação coerente à perspectiva positivista. Sendo assim, acredita-se que a pesquisa conseguiu alcançar o objetivo proposto.

Quanto aos interesses que motivaram as dissertações investigadas, identificou-se um predomínio pelo interesse técnico corroborando com as premissas advindas do posicionamento ou paradigma positivista. Por sua vez, esse interesse norteia a pesquisa segundo premissas de controle e predição de eventos, típicos dos métodos utilizados pelas ciências naturais. Além disso, tal interesse exclui o sujeito cognoscente, tornandoo coisificado ou um ente fora das dimensões sociais, culturais e históricas.

Espera-se que a pesquisa tenha estimulado possíveis debates a partir de proposições que poderão servir de base reflexiva e crítica na formulação de um possível doutorado, dentre outros aspectos construtivos relativos ao PPGCI/UFPE, de maneira geral.

\section{Referências}

ARAÚjO, C. A. A. Correntes teóricas da Ciência da Informação. Ciência da Informação, Brasília, v. 38, n. 3, p. 192-204, set./dez. 2009.

BARDIN, L. Análise de conteúdo. Lisboa: Edições 70, 2004.

BRAZ, M. I. Dispositivos de memória para informação jurídica: análise de procedimentos de indexação. 2013. 192 f. Dissertação (Mestrado em Ciência da Informação) - Centro de Artes e Comunicação, Universidade Federal de Pernambuco, Recife, 2013.

CORAZZA, M. J.; NEVES, M. C. D.; RAMOS, F. P. Os paradigmas da ciência moderna e pós-moderna e as concepções de professores-pesquisadores.

In: ENCONTRO NACIONAL DE PESQUISA EM EDUCAÇÃO EM CIÊNCIAS, 7., Belo Horizonte, nov. 2009. Anais... Belo Horizonte: ENPEC, 2009. p.1-12.

Disponívelem:<http://posgrad.fae.ufmg.br/posgrad/viienpec/pdfs/629.pdf >. Acesso em: 10 jan. 2014.

FELL, A. F. A; XIMENES, A. F.; FILHO, J. R. Pesquisa qualitativa em sistemas de informação (S.I.) no Brasil: uma análise da produção acadêmica. In: SIMPEP, 11., Bauru, São Paulo, 2004. Anais... São Paulo: UNESP, 2004. 1-13.

GIL, A. C. Métodos e técnicas de pesquisa social. São Paulo: Atlas, 2008.

GUBA, E.G.; LINCOLN, Y.S. Competing paradigms in qualitative research. In: DENZIN, N. K., LINCOLN, Y.S. (Eds.). Handbook of qualitative research. Thousand Oaks: Sage, 1994. 105-117.

HABERMAS, J. Knowledge and human interests. Boston: Beacon Press, 1971. 
Paradigmas e interesses do conhecimento na Ciência da Informação: um estudo sobre as dissertações de mestrado do Programa de PósGraduação em Ciência da Informação da Universidade Federal de Pernambuco (2011 a 2013)

HEER, F. História das civilizações. Lisboa: Arcádia, 1968. v. 3.

KUHN, T. A estrutura das revoluções científicas. São Paulo: Perspectiva, 2011.

MATTAR, F. N. Pesquisa de marketing: metodologia, planejamento. 6. ed. São Paulo: Atlas, 2005.

MEDEIROS, A. M. S.; MARQUES, M. A. R. B. Habermas e a teoria do conhecimento. Educação Temática Digital, v. 5, n. 1, p. 1-24, dez. 2003.

MUELLER, S. P. M.; CAMPELLO, B. S. C.; DIAS, E. J. W. Disseminação da pesquisa em Ciência da Informação e biblioteconomia no Brasil. Ciência da Informação, v. 5, n. 3, p. 1-23, 1996.

NOBRE, M. A teoria crítica. Campinas: Zahar, 2011. (Filosofia: passo a passo)

ORLIKOWSKI, W. J.; BAROUDI, J. J. Studying information technology in organizations: research approaches and assumptios. Information Systems Research, v. 2, n. 1, p.1-28, 1991.

PINHEIRO, L. V. R; LOUREIRO, J. M. M. Traçados e limites da Ciência da Informação. Ciência da Informação, v. 24, n. 1, p. 1-19, 1995.

PRIMON, A. L. M. et al. História da ciência: da idade média à atualidade. PsicológoInFormação, n. 4, ano 4, jun/dez. 2002.

QUEIROZ, M. O. Gestão da informação para a organização do conhecimento no terceiro setor: um estudo de caso na AERPA. 2013. 288 f. Dissertação (Mestrado em Ciência da Informação) - Centro de Artes e Comunicação, Universidade Federal de Pernambuco, Recife, 2013.

RODRIGUES FILHO, J. Desenvolvimento de diferentes perspectivas teóricas para análise das organizações. In: ENCONTRO DA ASSOCIAÇÃO NACIONAL DE PÓS-GRADUAÇÃO E PESQUISA EM ADMINISTRAÇÃO, 21., Rio das Pedras, 1997. Anais... Rio das Pedras: ENANPAD, 1997. p. 1-11. Disponível em: <http://www.anpad.org.br/diversos/trabalhos/EnANPAD/enanpad_1997/O RG/1997_ORG3.pdf>. Acesso em: 20 jul. 2016.

RUDIO, F. V. Introdução ao projeto de pesquisa científica. 9. ed. Petrópolis: Vozes, 1985.

SILVA, V. F. Informação e memória na literatura do cordel: produção e fluxo. 2012. 168 f. Dissertação (Mestrado em Ciência da Informação) Centro de Artes e Comunicação, Universidade Federal de Pernambuco, Recife, 2012.

YIN, R. K. Estudo de caso: planejamento e método. Porto Alegre: Bookman, 2005. 